\title{
Influence of AIDET in the improving quality metrics in a small community hospital - before and after analysis
}

\author{
Raul Zamora *, Mitun Patel, Bryan Doherty, Adam Alperstein, Peter Devito \\ Valleycare Health Systems of Ohio, Northside Medical Center, Youngstown, Ohio, United States
}

Received: May 27, 2014

Accepted: March 13, 2015

Online Published: April 8, 2015

DOI: $10.5430 /$ jha.v4n3p35

URL: http://dx.doi.org/10.5430/jha.v4n3p35

\begin{abstract}
Background: As the US healthcare system is becoming a more outcomes based system, increasing emphasis is being paid to improving all aspects of health care delivery. Interpersonal and communication skills, an ACGME (Accreditation Council for Graduate Medical Education) core competency in resident education, play a fundamental role in this effort. This aspect of healthcare delivery is also part of Medicare hospital reviews. In our hospital, the administration has introduced AIDET (Acknowledge, Introduce, Duration, Explanation, and Thank you) as a communication strategy which promises to improve exchange of information between healthcare professionals as well as with patients and their families. Objective: Determine if the AIDET strategy used in our facility has improved patient satisfaction.

Methods: This study was done using pretest post test experimental design. Patient satisfaction was measured using scores from the HCAHPS (Hospital Consumer Assessment of Healthcare Providers and Systems) quarterly reports from the $3^{\text {rd }}$ quarter of 2010 to the $2^{\text {nd }}$ quarter of 2013. Pre and post AIDET implementation results were statistically analysed using a paired $t$-test. Results are reported as a $p$-value with $<.05$ being statistically significant.

Results: There were a total of 1,811 patient responses sampled from the $3^{\text {rd }}$ quarter of 2010 to the $2^{\text {nd }}$ quarter of 2013. A significant change $<.05$ was seen in the way Nurses Explain, Doctors Explain and Nurses listen in the pre and post AIDET implementation comparison. The change in percentage of patients that believed doctors and nurses explained things to them in a way they could understand showed a $p$-value of .02 . The trend in percentage of patients that perceived that nurses always listened carefully to them showed a $p$-value of .02 as well. On the other hand, the data evaluating how doctors listened carefully to them did not reach statistical significance with a $p$-value of .08 . The remaining categories of "Told About Medication" and "Help after Discharge" were both found not have changed significantly either.

Conclusions: The implementation of AIDET education may have had a significant impact on provider-patient communication in our facility, especially in the patient's perception of explaining things in a way they could understand. On the other hand, in the responses to the question of whether or not doctors listened carefully to them, there was some improvement over time, however this did not achieve statistical significance.
\end{abstract}

Key Words: Communication, Quality, Patient satisfaction

\section{INTRODUCTION}

As the US healthcare system is becoming a more performance based system, a great focus has been placed in finding new strategies to improve measurable outcomes. These outcomes will undoubtedly be linked to an index of health and satisfaction. Physician communication, or lack of it, is one

\footnotetext{
*Correspondence: Raul Zamora; Email: razamo01@yahoo.com; Address: Valleycare Health Systems of Ohio, Northside Medical Center, Youngstown, Ohio, United States.
} 
of the most important factors of patient compliance, and therefore successful maintenance of health. According to the 2005 Mayo Clinic Proceedings, $72 \%$ of patients are unable to list their medications and $58 \%$ are unable to recite their own diagnosis. ${ }^{[1]}$ This is not beneficial to the system or the patient. AIDET (Acknowledge, Introduce, Duration, Explanation, and Thank you) is a communication strategy which promises to improve exchange of information between healthcare professionals with patients and their families, as well as with each other.

This communication framework was first developed by Quint Studer, a former teacher turned hospital administrator, who gained notoriety for bringing about an improvement in patient satisfaction from 40 to 99 percent at Baptist Memorial Hospital in the late 1990's. Since then, his concepts have been adopted by numerous healthcare institutions across the country. The AIDET practice, in particular, seems to correlate with patient satisfaction. ${ }^{[2]}$ One example of organizational success was shown at Witham Memorial Hospital, IN, where the radiology department implemented AIDET after a low quarterly patient satisfaction score report in 2010 . Patient satisfaction scores then rose $2.4 \%$ and remained relatively consistent from that point onward. After seeing this heightened patient satisfaction, the hospital administration went on to implement AIDET throughout the entire organization. ${ }^{[3]}$ In 2007, University Medical Center in Tucson, AZ, also reported at massive jump in patient satisfaction, from $12 \%$ to $38 \%$, only one month following physician and staff AIDET training. ${ }^{[4]}$

Not only does AIDET increase patient satisfaction, but can also have a positive impact on delivery of care. A pre and post-AIDET implementation study at Oklahoma University showed staggering results such as; ease of obtaining test results increased by $60 \%$, access to care increased by $46.5 \%$, and overall patient satisfaction also increased by $53 \%$. ${ }^{[5]}$

AIDET may also stimulate a tremendous return on investment. Southwest Washington M.C., in Vancouver, WA, reported their annual up-front co-pay collections increased $\$ 136,420$ after AIDET implementation. ${ }^{[6]}$ It also reduces litigation costs, since the risk of most malpractice suits is predicted by practitioners' inability to communicate well with their patients. ${ }^{[7,8]}$ A reported $50 \%$ decrease in complaints over a two quarter period at University Medical Center, Tuscon, after AIDET implementation is a testament to that. ${ }^{[4]}$

Northside Medical Center is a 389 beds, university-affiliated hospital in Youngstown, Ohio, offering a wide range of inpatient, outpatient, emergency, diagnostic and therapeutic services for patients throughout the Mahoning Valley. Northside is a Level III Trauma Center, Primary Stroke Center and accredited Chest Pain Center. Northside has been recognized as a Distinguished Hospital for Clinical Excellence ${ }^{T M}$ in 2013 by HealthGrades. This distinction puts Northside in the Top 5\% in the nation for its clinical performance, according to HealthGrades. In our strive for improved performance, patient satisfaction is of great importance to our institution.

In November of 2011, as part of the Community hospital systems (CHS), Northside medical center began employee education about the concept of AIDET. This involved a $60 \mathrm{~min}$ lecture on this topic at the beginning of employment, with a yearly mandatory online review course. The goal of this study is to evaluate whether implementation of AIDET has in fact improved patient satisfaction in our facility, most specifically patient-provider communication.

\section{Methods}

Our study had a pretest- post test experimental design. Patient satisfaction was measured using the HCAHPS (Hospital Consumer Assessment of Healthcare Providers and Systems) quarterly reports. HCAHPS reports were developed by the Centers for Medicare \& Medicaid Services (CMS), along with the Agency for Healthcare Research and Quality, as a standardized survey instrument for measuring patients' perspectives on hospital care. The HCAHPS Survey is administered to a random sample of patients continuously throughout the year and encompasses critical aspects of the hospital experience, where communication is weighted heavily.

Communication data was measured by extracting the percentage of patient who responded "always" to the questions that evaluate listening and explaining skills in the communication with doctors and nurses section of the HCAHPS questionnaire. The questions that we included in our analysis were:

(1) During this hospital stay, how often did doctors listen carefully to you?

(2) During this hospital stay, how often did doctors explain things in a way you could understand?

(3) During this hospital stay, how often did nurses listen carefully to you?

(4) During this hospital stay, how often did nurses explain things in a way you could understand?

Pre and post AIDET implementation results were compared using a paired t-tests analysis. The test was run under the null hypothesis that there is no relationship on communication between health care workers and patients before the implementation of AIDET (null hypothesis). The p-values were calculated for each variable with $p$-values $<.05$ being determined a significant difference. The software used for the 
calculations was the 2014 version of the XLSTAT application for Microsoft Excel.

\section{Results}

The total sample size during the period of time evaluated included 1811 responses. From the $3^{\text {rd }}$ quarter of 2010 to the $2^{\text {nd }}$ quarter of 2013 the quarterly sample sizes were 167,171 , 156, 160, 171, 198, 199, 203, 201, and 185. These responses corresponded to $39.5 \%, 25 \%, 27 \%, 29 \%, 27 \%, 34 \%, 32 \%$, $33 \%, 33 \%$, and $30 \%$ respectively; from all patients that were attempted.

Using the Communication with Doctors section of the HCAHPS score we noted that there was an improvement in scores prior to and after the implementation of AIDET. The change in percentage of patients that believed doctors explained things to them in a way they could understand, starting from the $3^{\text {rd }}$ quarter of 2010 to the $2^{\text {nd }}$ quarter of 2013 , was statistically significant. The raw percentages were $68 \%$, $69 \%, 62 \%, 74 \%, 71 \%, 72 \%, 78 \%, 74 \%, 78 \%, 75 \%, 74 \%$ and $83 \%$. This trend is depicted in Figure 1. The analysis showed a statistical difference with a $p$-value of .02 .

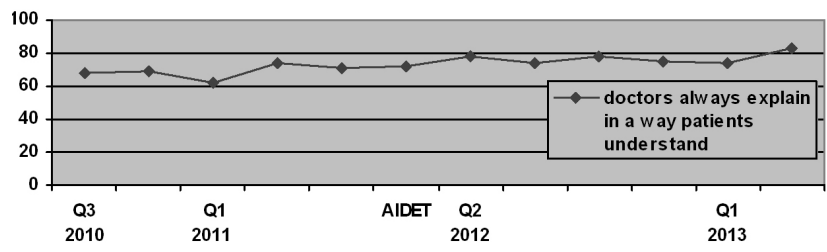

Figure 1. Percentage of patients who responded "always" to the "doctors explain" question over time

Regarding the analysis of the percentage of patients that perceived that doctors always listened carefully to them during the same period, was not statistically significant. Although there was a trend towards improvement, the $p$-value was .08. The percentages were $70 \%, 76 \%, 69 \%, 80 \%, 77 \%, 79 \%$, $79 \%, 75 \%, 76 \%, 78 \%, 81 \%$, and $86 \%$ respectively. This is illustrated in Figure 2.

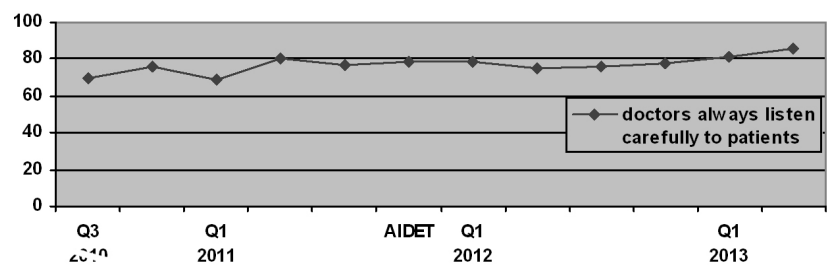

Figure 2. Percentage of patients who responded "always" to the "doctors listen" question over time

HCAPHS data evaluating how nurses explained things to patients in a way patients could understand did show statistically significant improvement. The percentages of patients Published by Sciedu Press who believe they did were $64 \%, 62 \%, 61 \%, 76 \%, 72 \%, 81 \%$, $78 \%, 79 \%, 75 \%, 74 \%, 74 \%$, and $89 \%$ during the study period. This is illustrated in Figure 3 and the $p$-value was .02 .

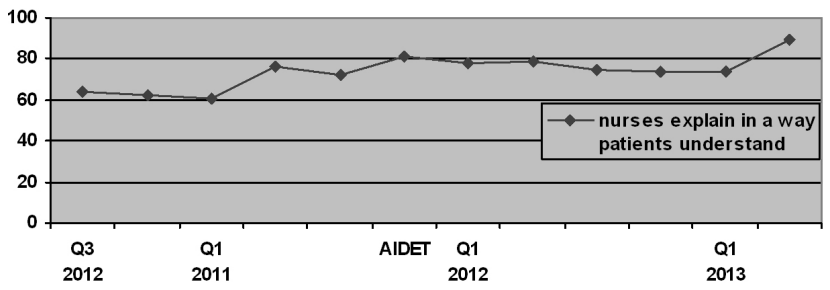

Figure 3. Percentage of patients who responded "always" to the "nurses explain" question over time

The trend in the percentage of patients who thought nurses listened carefully to them showed a statistically significant improvement as well. The raw percentages from the HCAPHS questionnaire during the period of the study were $66 \%, 62 \%$, $61 \%, 72 \%, 79 \%, 80 \%, 84 \%, 83 \%, 79 \%, 77 \%, 80 \%$, and $83 \%$ $(p=.02)$ (see Figure 4).

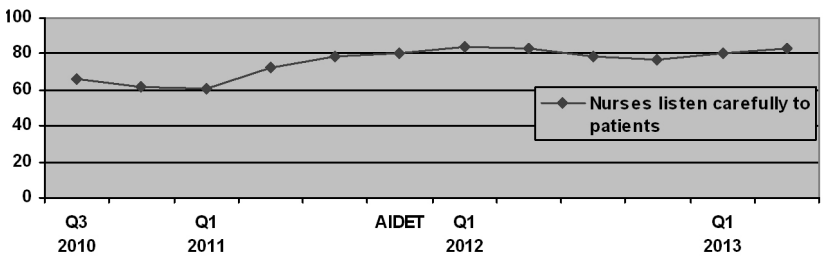

Figure 4. Percentage of patients who responded "always" to the "nurses listen" question over time

Table 1. Shows the communication categories that were included in the AIDET quality improvement project

\begin{tabular}{ll}
\hline Category & $\boldsymbol{p}$-value \\
\hline Nurses Explain & .029 \\
Doctors Explain & .020 \\
Doctors Listen & .084 \\
Nurses Listen & .029 \\
\hline
\end{tabular}

\section{Discussion}

Above results show that the implementation of AIDET education may have had a significant impact on provider patient communication in our facility (see Table 1). Of course, there could be several confounding factors, including the Hawthorne effect. Yet, it serves us all well to make sure we are providing the best care possible to our population, and if knowing our behavior is being observed and evaluated helps in achieving this goal, so be it.

Unfortunately, not all aspects of communication achieved statistically significant improvement. This could be a result 
of the few data points accrued during these three year period. Perhaps if we were able to obtain more frequent reports, as compared to Quarterly reports, the trend could achieve statistical significance.

Our study is limited by the retrospective nature of the data collection. About $1 / 3$ of attempted subjects per quarter were included in the sample, which is obviously seems low. It would be fair to question if these patients were the ones that had stronger opinions one way or the other, introducing some selection bias. These percentages of responders remained constant over the entire period of the study.

Why are listening skills lagging behind? A factor that could partially account for this shortcoming in communication could be the also important aim to be more time efficient in the daily interaction with patients. Even in medical school physicians are taught to limit patient communication to the problem at hand. Yet, this is seldom the reality. Patient's often have many questions which are not always concerning the actual medical problem. It's also not uncommon to see a physician come into a patient's room, update the patient regarding his or her medical condition, lab results, etc; then leave the room to see another patient. These clinical behaviors could be perceived as a lack of listening skills by patients and physicians need to be aware of this.

How much time we really spend with the patient could also be a factor. ${ }^{[9]}$ The fact that nurses had consistently higher scores in this aspect is concordant with the duration of interaction as a reflection of listening perception by the patient. It is important not only to recognize the fact that the mere amount of time spent with a patient is important to them, but perhaps we should do something about it. As our health system becomes a pay for performance system, physicians no longer will be more rewarded for seeing a higher number of patients, but based on outcomes and likely patient perception. Maybe expending some extra time sitting in a patient room once in a while, and just listening would do the trick.

\section{Future studies}

Continue to explore the reasons why patients don't perceive doctors listening enough, and institution initiatives aiming at improving outcomes.

\section{REFERENCES}

[1] Makaryus A, Friedman EA. Patients' Understanding of Their Treatment Plans and Diagnosis at Discharge. Mayo Clin Proc. Aug 2005; 80(8): 991-4. PMid: 16092576. http://dx.doi.org/10.4065/8 0.8 .991

[2] Studer Group AIDET product evaluation survey of Partners and Non-Partners. 2010.

[3] Scott Jason. Utilizing AIDET and Other Tools to Increase Patient Satisfaction Scores. Radiology Management. May/June 2012; 34(3): 29-33.

[4] Studer Group AIDET product evaluation survey of Partners and Non-partners. 2007.

[5] Judy B, Joan K. Moving HCAHPS results, One "Composite Owner" at a Time. Studer Group's annual "What's Right in Health Care" conference; Chicago, 2008.

[6] Craig D. Closing the Knowing- Doing Gap. 2014 Quality New Mexico Learning Summit. Albuquerque: New Mexico; April 2014.

[7] Hickson GB, Jenkins AD. Identifying and addressing communication failures as a means of reducing unnecessary malpractice claims. NC Med J. 2007; 68: 362-364. PMid: 18183762.

[8] Levinson W, Roter DL, Mullooly JP. Physician-patient communication. The relationship with malpractice claims among primary care physicians and surgeons. JAMA. 1997; 277: 553-559. PMid: 9032162. http://dx.doi.org/10.1001/jama.1997.0354031 0051034

[9] Murphy A. To sit or not to sit? a question of cultural performance. Ann Emerg Med. 2008 Feb;51(2):194-6 Ann Emerg Med. Feb 2008; 51(2): 194-6. PMid: 17719692. http://dx.doi.org/10.1016/j .annemergmed.2007.06.477 